\title{
PRODUÇÃO DE BIOETANOL COMBUSTÍVEL POR BATELADA ALIMENTADA UTILIZANDO SACCHAROMYCES CEREVISIAE SUPORTADO EM ESFERAS DE ALGINATO DE CÁLCIO REVESTIDAS COM QUITOSA.
}

\author{
L. A. K. OURA ${ }^{1}$, T. S. BELLA DE JESUS ${ }^{1}$, J. R. NUNHEZ ${ }^{1}$, G. P. VALENÇA ${ }^{1}$, \\ L. C. FARDELONE ${ }^{2}$, J. A. R. RODRIGUES ${ }^{2}$ e P. J. S. MORAN ${ }^{2}$ \\ ${ }^{1}$ Universidade Estadual de Campinas, Faculdade Engenharia Química \\ ${ }^{2}$ Universidade Estadual de Campinas, Instituto de Química \\ E-mail para contato: lucidio.fardelone@iqm.unicamp.br
}

\begin{abstract}
RESUMO - Células imobilizadas de Saccharomyces cerevisiae em esferas de alginato de cálcio revestidas com quitosana foram utilizadas para o desenvolvimento de processo de produção de bioetanol combustível. Estes processos de bateladas alimentadas foram conduzidos por 96 horas, fornecendo rendimentos de $89-95 \%$.
\end{abstract}

\section{INTRODUÇÃO}

O uso de células imobilizadas em processos de produção de bioetanol combustível vem sendo estudado para obtenção de ganho de produção (Lee et al., 2015; Duarte et al., 2013; Ghorbani et al., 2011; Nikolic et al., 2010; Wendhausen et al., 2000; Tyagi et al., 1992). Normalmente sistemas de fermentação que utilizam suportes celulares promovem maior tempo de processo e consequentemente maior produtividade, simplificam a separação e purificação dos produtos. Na literatura estão descritas técnicas de produção de bioetanol utilizando suportes e técnicas de imobilização utilizando alginato de sódio (Duarte et al., 2013; Călinescu et al., 2012; Najafpour et al., 2004), bem como o alginato de sódio é utilizado em processos industriais para produtos alimentícios e farmacêuticos (Najafpour et al., 2004; Kubota et al., 2000).

Neste trabalho, nós reportamos o processo de produção de bioetanol combustível utilizando a levedura Saccharomyces cerevisiae imobilizada em esferas de alginato de cálcio recobertas com quitosana, utilizando ácido cítrico para solubilização quitosana e no recobrimento das esferas. O processo fermentativo desenvolvido conferiu alta resistência do suporte celular para ser utilizados em processos mais longos, forneceu alta produtividade de bioetanol devido a alta conversão da glicose, além de facilitar a separação do produto do meio fermentativo, o que demonstra ser possível a otimização do processo para maior escala.

\section{METODOLOGIA}

Foi utilizada a cepa JAY270 de $S$. cerevisiae, fornecida pelo Instituto de Biologia da Unicamp (IB), que possui alta resistência à temperatura elevadas, variação de $\mathrm{pH}$, estresse oxidativo, alta produção de massa celular e de bioetanol (Duarte et al. 2013; Argueso et al. 
2009). Os reagentes ácido cítrico, cloreto de cálcio, alginato de sódio (viscosidade média) e quitosana (peso molecular médio, grau de desacetilação 75-85\%) foram adquiridos da Sigma-Aldrich Co, glicose da Synth, extrato de levedura, extrato de malte e peptona da BD Bioscience.

Para a expansão celular da levedura $S$. cerevisae foi utilizado meio de cultura com composição de $3,0 \mathrm{~g} / \mathrm{L}$ de extrato de malte, $3,0 \mathrm{~g} / \mathrm{L}$ de extrato de levedura, $5,0 \mathrm{~g} / \mathrm{L}$ peptona e $10 \mathrm{~g} / \mathrm{L}$ glicose, ajustado o $\mathrm{pH}$ para 6,0, mantendo os erlenmeyers com reentrâncias (baffled flask), para melhor mistura, com $120 \mathrm{rpm}(0,54 \mathrm{~g})$ em shaker por $18 \mathrm{~h}$. Após o crescimento da massa celular, esta foi centrifugada, $1844 \mathrm{~g}$ por 20 minutos, sob medidas de assepsia, sendo que as células obtidas $(30 \mathrm{~g})$ foram utilizadas para imobilização em alginato de cálcio, seguido de revestimento com quitosana, a qual foi solubilizada com ácido cítrico (Duarte et al. 2013; Nagashima et al., 1984).

A técnica utilizada para imobilização das células foi por aprisionamento em matriz porosa, através do uso de uma suspensão de alginato de sódio $3 \%$ e de S. cerevisiae, gotejada em solução de cloreto de cálcio, $\mathrm{CaCl}_{2} 2 \%$, formando esferas com diâmetro de aproximadamente 3-4 mm. As esferas foram mantidas em solução de $\mathrm{CaCl}_{2} 2 \%$, por 1 hora para que ocorresse uma melhor distribuição do cálcio no gel da matriz de suporte celular. Seguido de 30 minutos em solução de quitosana com ácido cítrico para o revestimento.

Para que as esferas apresentassem uma melhor performance durante o processo fermentativo, e para que diminuísse a lixiviação do cálcio presente na rede polimérica das esferas, estas foram curadas de duas maneiras diferentes, após o recobrimento com quitosana solubilizada em ácido cítrico, uma mantendo-se por 1 hora as esferas em solução de $\mathrm{CaCl}_{2} 2 \%$ e outra por 30 minutos. Em seguida, as esferas foram separadas por filtração, lavadas com água destilada e utilizadas nos processos fermentativos.

As fermentações foram conduzidas de 4 maneiras diferentes, uma como controle utilizando as esferas de alginato de cálcio revestidas com quitosana, tal qual, uma utilizando o as esferas que passaram por cura por 30 minutos em $\mathrm{CaCl}_{2} 2 \%$, uma com a cura por 1 hora e a outra utilizando esferas de alginato de cálcio revestidas com quitosana (conforme o controle), mas com adição de $5 \mathrm{~g}$ de $\mathrm{CaCl}_{2}$ ao meio fermentativo.

A concentração final de etanol e de glicose residual foram determinadas através de Cromatografia Líquida de Alta Eficiência (CLAE) utilizando o equipamento Agilent Technologies 1200 Series, com sistema de injeção automático, detector com índice de refração, acoplado a coluna Aminex $\mathrm{HPX}-87 \mathrm{H}, 300$ x 7,8 mm, mantida à temperatura de $50{ }^{\circ} \mathrm{C}$, utilizando como fase móvel solução $0,005 \mathrm{~mol} / \mathrm{L}$ de $\mathrm{H}_{2} \mathrm{SO}_{4}$, sob fluxo de $0,6 \mathrm{~mL} / \mathrm{min}$.

\section{RESULTADOS E DISCUSSÃO}

Os processos fermentativos utilizando células imobilizadas de $S$. cerevisiae em alginato de cálcio revestidos com quitosana foram realizados nas mesmas condições utilizando 4,6 g de peso de células da levedura imobilizadas, $111 \mathrm{~g} / \mathrm{L}$ de glicose inicial e adições a cada 24 horas de 142,0 g/L de glicose (concentrações determinadas por CLAE), $\mathrm{pH}$ 6, utilizando shaker a $120 \mathrm{rpm}(0,54 \mathrm{~g}), 30^{\circ} \mathrm{C}$, por $96 \mathrm{~h}$. 


\section{Congresso Brasileiro de Engenharia Química \\ em Iniciação Científica \\ UFSCar - São Carlos - SP \\ 16 a 19 de Julho de 2017}

Na Figura 1, estão demonstrados os perfis de produtividades de bioetanol ao longo de 96 horas nos processos de bateladas alimentadas e na Tabela 1, estão demonstrados os rendimentos, concentrações finais de bioetanol e de glicose residual. $\mathrm{O}$ rendimento final foi definido através do bioetanol produzido em relação ao máximo de conversão da fonte de carbono, glicose, em bioetanol. Sendo observado alta conversão da fonte de carbono (glicose) ao final dos processos fermentativos, $89-95 \%$ de rendimento.

Figura 1 - Processos em batelada alimentada de produção de bioetanol combustível por $S$. cerevisiae suportados em esferas de alginato de cálcio revestido com quitosana.

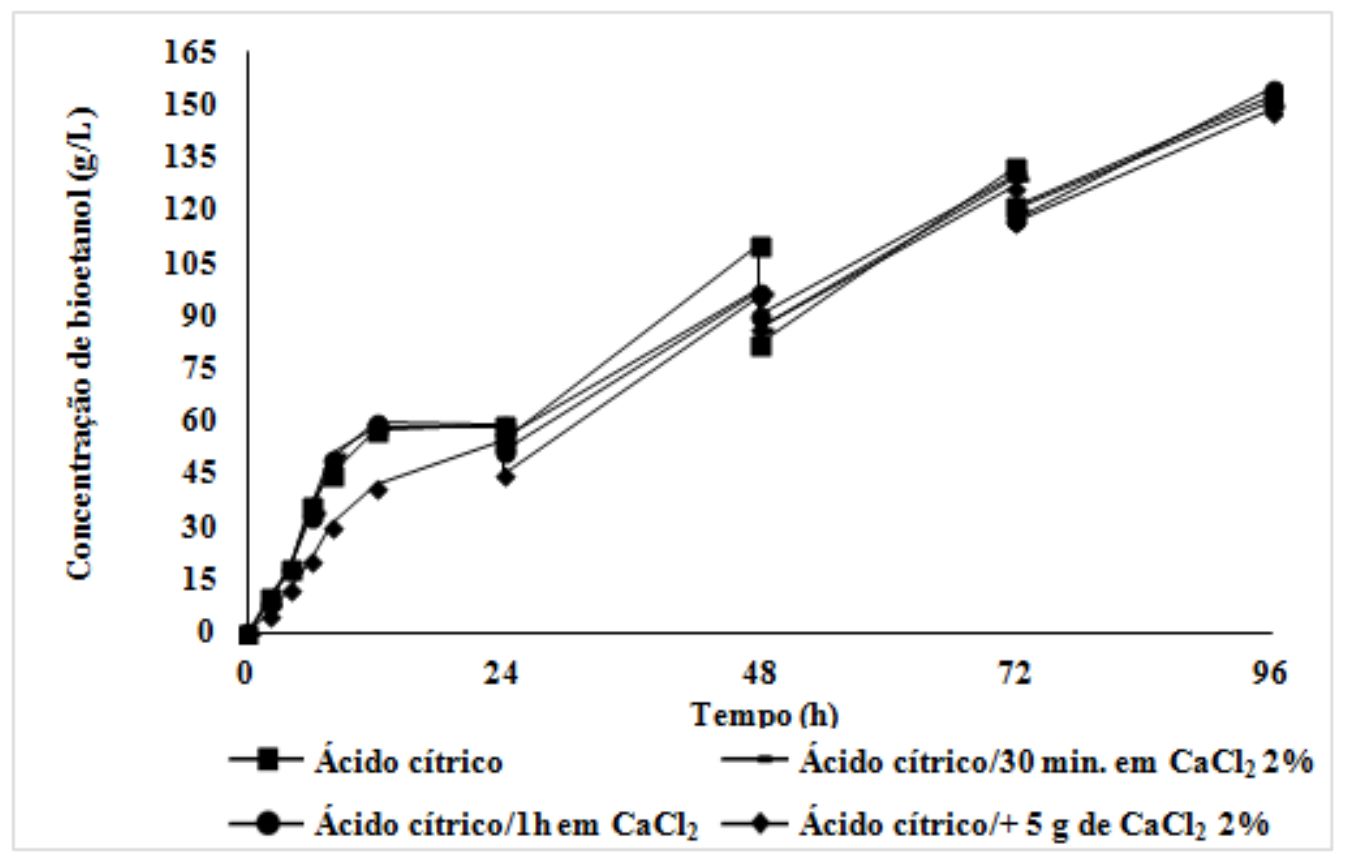

As inserções, $24 \mathrm{~h}, 48 \mathrm{~h}, 72 \mathrm{~h}$ são referentes as adições de glicose para que o processo mantivesse uma produção contínua de bioetanol combustível.

Tabela 1 - Resultados de produção de bioetanol combustível por S. cerevisiae suportados em esferas de alginato de cálcio revestido com quitosana.

\begin{tabular}{|c|c|c|c|}
\hline Células de $S$. cerevisiae & $\begin{array}{c}\text { Glicose residual } \\
(\mathrm{g} / \mathrm{L}) \text { após } 96 \mathrm{~h}\end{array}$ & $\begin{array}{c}\text { Bioetanol } \\
(\mathrm{g} / \mathrm{L}) \text { após } 96 \mathrm{~h}\end{array}$ & $\begin{array}{c}\text { Rendimento em bioetanol } \\
(\%)\end{array}$ \\
\hline $\begin{array}{c}\text { Imobilizadas em alginato/ revestida com } \\
\text { quitosana/ác. cítrico }\end{array}$ & 0 & 152,4 & 93 \\
\hline $\begin{array}{c}\text { Imobilizadas em alginato/ revestida com } \\
\text { quitosana/ác. cítrico/ } 30 \text { min. em CaCl } \\
2 \%\end{array}$ & 0 & 150,9 & 89 \\
\hline $\begin{array}{c}\text { Imobilizadas em alginato/ revestida com } \\
\text { quitosana/ác. cítrico/ } 1 \mathrm{~h} \text { em } \mathrm{CaCl}_{2} 2 \%\end{array}$ & 0 & 155,2 & 95 \\
\hline $\begin{array}{c}\text { Imobilizadas em alginato/ revestida com } \\
\text { quitosana/ác. cítrico }+5 \mathrm{~g} \text { de } \mathrm{CaCl}_{2}\end{array}$ & 0,6 & 148,9 & 91,2 \\
\hline
\end{tabular}


Na Figura 2 estão representadas imagens do início do processo e após 96 horas de produção de bioetanol combustível e é possível observar que poucas esferas estão rompidas, o que confere maior robustez ao processo.

Figura 2 - a Esferas de alginato de cálcio como suporte para $S$. cerevisiae no início do processo fermentativo para produção de bioetanol combustível; b esferas de alginato de cálcio como suporte para $S$. cerevisiae após 96 h de processo fermentativo; cesferas de alginato de cálcio como suporte para $S$. cerevisiae curadas por 1 hora em $\mathrm{CaCl}_{2} 2 \%$, após 96 horas de processo; d esferas de alginato de cálcio como suporte para $S$. cerevisiae curadas por 30 minutos em $\mathrm{CaCl}_{2}$, após 96 horas de processo; e esferas de alginato de cálcio como suporte

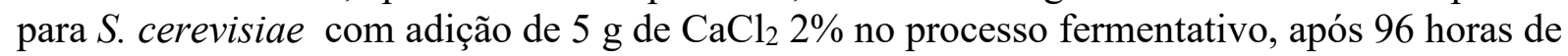
processo.

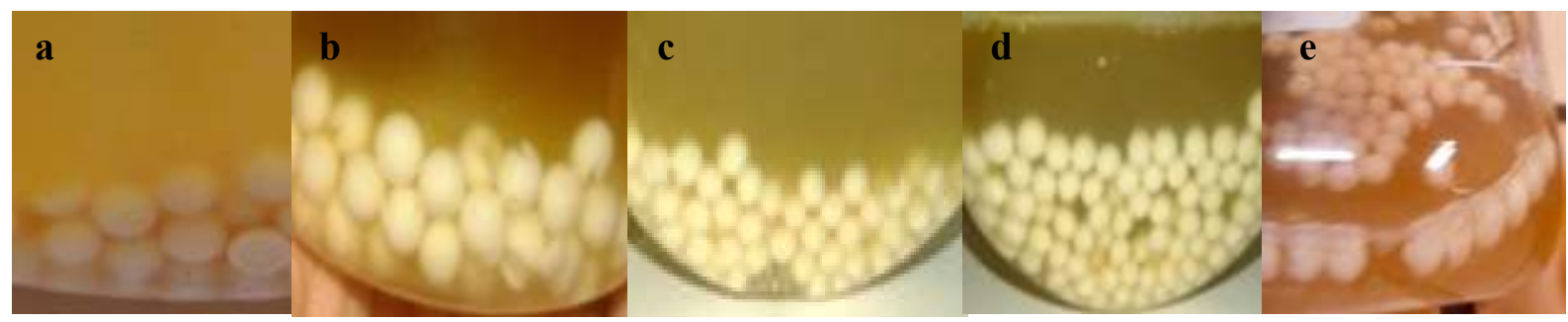

Normalmente quando se utiliza ácido acético no processo de recobrimento da quitosana nas esferas, há um residual do ácido acético, provocando uma maior fase lag, para o início da produção de bioetanol (Duarte et al., 2013), assim, a utilização do ácido cítrico em substituição ao ácido acético promoveu a diminuição desta fase de adaptação das células para produção de bioetanol, Figura 3.

Figura 3 - Processos em batelada de produção de bioetanol combustível por S. cerevisiae suportados em esferas de alginato de cálcio e alginato de cálcio revestido com quitosana.

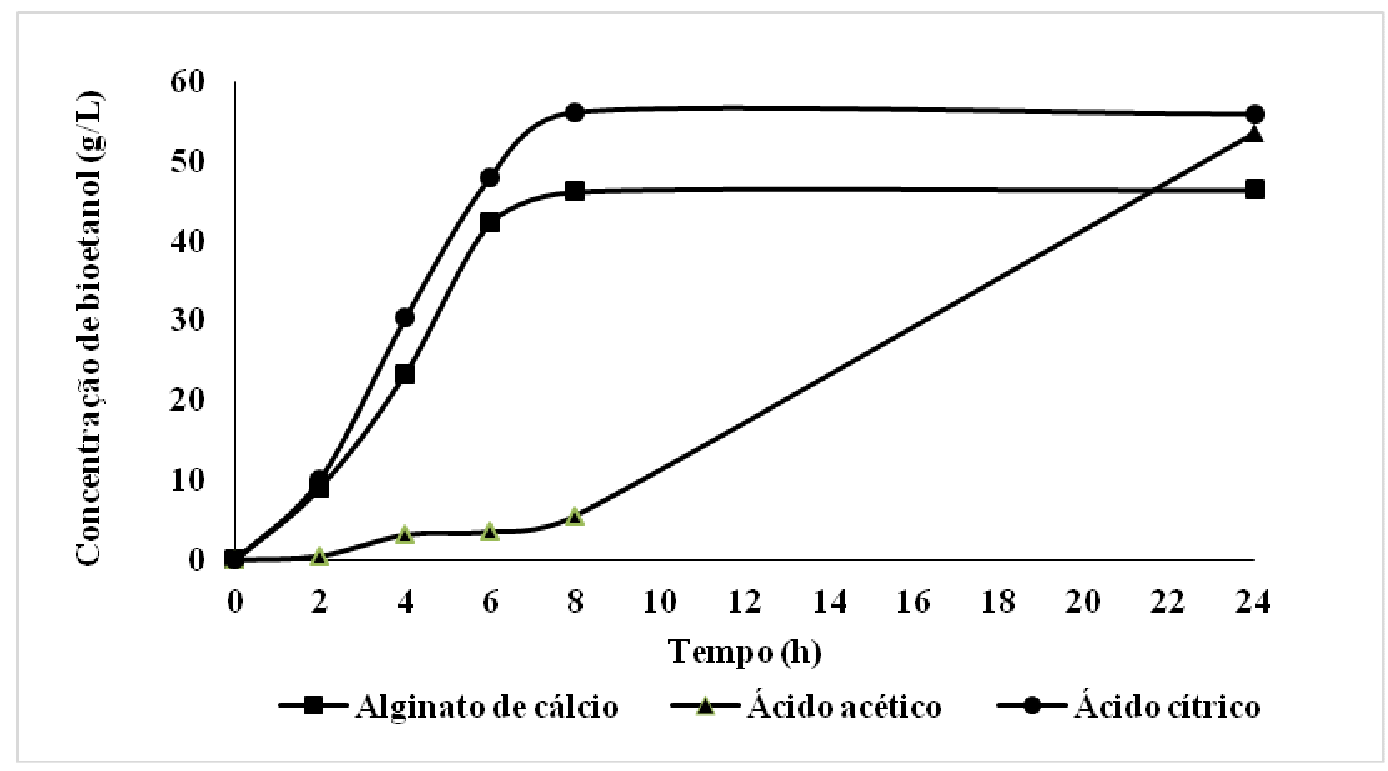




\section{CONCLUSÕES}

O processo de produção de bioetanol combustível utilizando células de $S$. cerevisiae imobilizadas em alginato de cálcio, utilizando ácido cítrico no processo de imobilização e curadas com cloreto de cálcio, bem como, com adição de cloreto de cálcio no meio de cultura, promoveram maior robustez ao processo, isto é, forneceram maior resistência ao suporte utilizado, diminuindo a lixiviação do cálcio da matriz de imobilização, bem como maior produtividade de bioetanol. Este processo será ampliado e otimizado para biorreatores e os resultados serão reportados futuramente.

\section{AGRADECIMENTOS}

Os autores agradecem os suportes financeiros do projeto pela FAPESP (2016/120747), CAPES e CNPq.

\section{REFERÊNCIAS}

ARGUESO J. L.; CARAZZOLlE, M. F.; MIECZKOWSKI, P. A.; DUARTE, F. M.; NETTO, O. V. C.; MISSAWA, S. K.; GALZERANI, F.; COSTA, G. G. L.; VIDAL, R. O.; NORONHA, M. F; DOMINSKA, M.; ANDRIETTA, M. G.S.; ANDRIETTA; S. R.; CUNHA, A. F.; GOMES, L. H.; TAVARES, F. C. A.; AlCARDE, A. R.; DIETRICH, F. S.; MCCUSKER, J. H; PEREIRA, G. A. G. Genome structure of a Saccharomyces cerevisiae strain widely used in bioethanol production. Gen. Res., v. 19, p. 2258-2270, 2009.

CĂLINESCU,I., CHIPURICI, P., TRIFAN, A., BĂDOIU, C. Immobilization of Saccharomyces cerevisiae for the production of bioethanol. U.P.B. Sci. Bull., Series B 74, 33-40, 2012.

DUARTE, J. C.; RODRIGUES, J. A. R.; MORAN, P. J. S.; VALENÇA, G. P.; NUNHEZ, J. R. Effect of immobilized cells in calcium alginate beads in alcoholic fermentation. ABM Express, , v. 31, p. 1-8, 2013.

GHORBANI, F.; YOUNESI, H.; SARI, A. E.; NAJAFPOUR, G. Cane molasses fermentation for continuous ethanol production in an immobilized cells reactor by Saccharomyces cerevisiae. Ren. Energy, v. 36, p. 503-509, 2011.

KUBOTA, N.; TATSUMOTO, N.; SANO, T.; TOYA, K. A. Simple preparation of half $\mathrm{N}$-acetylated chitosan highly soluble in water and aqueous organic solvent. Carb. Res., p. 268-274, 2000.

LEE, H.; KIM, S.; YOON, J.; KIM, K. H.; SEO, J.; PARK, Y. Evolutionary engineering of Saccharomyces cerevisiae for efficient conversion of red algal biosugars to bioethanol. Bioresour. Technol., v. 191, p. 445-451, 2015.

NAGASHIMA, M.; AZUMA, M.; NOGUCID, S; INUZUKA, K; SAMEJIMA, H. Continuous fermentation using immobilized yeast cells. Biot. Bioeng., v. 26, p. 992-997, 1984. 
NAJAFPOUR, G.; YOUNESI, H.; SYAHIDAH KU ISMAIL, K. Ethanol fermentation in an immobilized cell reactor using Saccharomyces cerevisiae. Biores. Technol., v. 92, p. 251-260, 2004.

NIKOLIC, S.; MOJOVIC, L.; PEJIN, D.; RAKIN, M.; VUKASINOVIC, M. Production of bioethanol from corn meal hydrolizates by free and immobilized cells of Saccharomyces cerevisiae var. ellipsoideus. Biomass Bioenerg., v. 34, p. 1449-1456, 2010 .

TYAGI, R. D.; GUPTAB S. K.; CHAND, S. Process engineering studies on continuous ethanol production by immobilized S. cerevisiae. Proc. Bioch., v. 27, p. 23-32, 1992.

WENDHAUSEN, R.; FREGONESI, A.; MORAN, P. J. S.; JOEKES, I.; RODRIGURES, J. A. R.; TONELLA, E.; ALTHOFF, K. Continuous Fermentation of Sugar Cane Syrup Using Immobilized Yeast Cells. J. Bio. Bioeng., v. 91, p. 48-52, 2000. 